\title{
A Systematic Review to Investigate Whether Angiotensin-(1-7) Is a Promising Therapeutic Target in Human Heart Failure
}

\author{
Vincent C. H. Lee, ${ }^{1}$ Elizabeth N. Lloyd, ${ }^{2}$ Helena C. Dearden, ${ }^{1}$ and Kenneth Wong ${ }^{1,2}$ \\ ${ }^{1}$ Hull York Medical School, Castle Hill Hospital, Castle Road, Kingston upon Hull HU16 5JQ, UK \\ ${ }^{2}$ Department of Cardiovascular and Respiratory Studies, Hull and East Yorkshire Medical Research and Teaching Centre, \\ Daisy Building, Castle Hill Hospital, Castle Road, Kingston upon Hull HU16 5JQ, UK
}

Correspondence should be addressed to Kenneth Wong; kenneth.wong@hey.nhs.uk

Received 1 May 2013; Accepted 29 July 2013

Academic Editor: Suhn Hee Kim

Copyright (C) 2013 Vincent C. H. Lee et al. This is an open access article distributed under the Creative Commons Attribution License, which permits unrestricted use, distribution, and reproduction in any medium, provided the original work is properly cited.

Context. Heart failure (HF) is a common condition causing much morbidity and mortality despite major advances in pharmacological and device therapies. Preclinical data suggest a cardioprotective role of Angiotensin-(1-7) in animal models of HF. Objective. Perform a systematic review on the effects of Angiotensin-(1-7) on humans, focusing on HF. Results. 39 studies were included in the review ( 4 in human HF and (35) in non-HF patients). There is only one intervention study on 8 patients with human HF, using Angiotensin-(1-7), with forearm blood flow (FBF) as the endpoint. Angiotensin-(1-7) caused no significant effect on FBF in this HF study but caused vasodilation in 3 out of 4 non-HF studies. In one other non-HF study, Angiotensin-(1-7) infusion led to a significant increase in blood pressure in normal men; however, effects were $<0.03 \%$ that of angiotensin II. Cardioprotective effects seen in non-HF studies include for instance beneficial actions against atherosclerosis and myocardial fibrosis. Conclusions. The main finding of our systematic review is that Angiotensin-(1-7) plays an important cardioprotective role in HF in animals and in patients without heart failure. More research is required to test the hypothesis that Angiotensin-(1-7) benefits patients with heart failure.

\section{Introduction}

Heart failure (HF) is a major health problem for many developed world populations and has a relatively poor prognosis. Within the US population, the incidence approaches $1 \%$, with a lifetime risk of 1 in 5 for both men and women at the age of 40 years [1]. In 2005, there was an estimated near 1.1 million admissions to American hospitals associated with HF, which was up from approximately 400,000 in 1979 [2]. This substantial increase in prevalence and hospitalisation meant an epidemic was declared $[3,4]$. Over the coming years, the prevalence is likely to increase due to changing lifestyles and diets of the developing world, advances in heart failure therapeutics, an increase in prevalence of conditions which have cardiovascular consequences such as obesity and diabetes, and better survival from other heart conditions where HF is the end stage especially with the increased use of primary angioplasty for myocardial infarction. Figures from the United States show an estimated bill totalling $\$ 39.2$ billion in 2010, to cover the direct and indirect cost of HF [5]. One in 8 death certificates in America mentioned HF, and in $20 \%$ of cases, it was the primary cause. In 2006, the number of anymention deaths from HF was 283,000 [1]. Five-year mortality is $45-60 \%$ [6], and hospitalisations increased in the months prior to their death [7]; moreover, after the first hospitalisation, the 5-year mortality was greater than $75 \%$ [8]. This deadly syndrome, where the renin-angiotensin-aldosterone system (RAAS) is of great importance, is characterised by dyspnoea, venous congestion, and oedema, the consequences of anatomical and functional defects within the heart.

1.1. Angiotensin-(1-7): The Peptide. This bioactive endogenous heptapeptide is taking increasing amounts of interest from investigators because of its potential as a therapeutic agent. Angiotensin-(1-7) (Ang-(1-7)) is becoming recognised as an increasingly important player of the RAAS where accumulating evidence suggests that it may have a key role in 
the regulation and homeostasis of the RAAS, exerting cardiovascular protection. Ang-(1-7) is different from angiotensin II due to the absence of an amino acid at position 8 , described as the most pleiotropic metabolite of angiotensin I (Ang I), and is known to have actions which on most occasions are opposite (but may be identical) of those known for angiotensin II (Ang II) [9, 10]. Many effects of Ang-(1-7) are mediated via the high-affinity $G$ protein-coupled receptor Mas, where Ang-(1-7) is an endogenous ligand [11]. Endopeptidases (such as neutral endopeptidase (NEP)) and angiotensin-converting enzyme-2 (ACE2) contribute to the alternative pathways of Ang-(1-7) generation, using the substrates angiotensin I (Ang I) and angiotensin II (Ang II), respectively [12-14], whereas it has been shown that Ang-(1-7) is degraded to angiotensin- 15 (Ang-(1-5)) by angiotensin-converting enzyme (ACE) [15]. In contrast, ACE has also been shown to generate Ang-(17) from angiotensin-(1-9) [16]. Ang-(1-7) studies have shown that it is a potential endogenous counterregulator of the RAAS cascade [15, 17]. Physiological concentration of Ang(1-7) in man is thought to be $10 \mathrm{pmol} / \mathrm{L}[18,19]$. In 1988 , Schiavone et al. suggested that Ang-(1-7) peptide was indeed biologically active [20], raising the possibility of potential benefits of Ang-(1-7).

1.2. Preclinical Studies. There has been an abundance of animal studies investigating the effects of Ang-(1-7) in a variety of environments. Increased activation of the RAAS in heart failure is a compensatory mechanism. However, this increased afterload can have adverse effects on cardiac function. Angiotensin converting enzyme inhibitors are commonly seen in the management plan of HF; one reason is to reduce arterial pressure and to reduce the levels of Ang II. Vasodilatation is a property of Ang-(1-7) [21]. It does so by various postulated mechanisms such as releasing nitric oxide (NO) and prostaglandins [22-25]. Both Brosnihan et al. [26] and Porsti et al. [27], by administering NO synthase inhibitors, suggested that the vasodilatory effect of Ang(1-7) may be at least partly dependent on the release of NO. Furthermore, Benter et al.s work would suggest that Ang-(1-7) might oppose the haemodynamic actions of Ang II. Another peptide contributing to the vasodilatory effects of Ang-(1-7) is bradykinin (BK) [29], a molecule Ang-(17) is shown to interact with. Paula and colleagues [30] suggested that Ang-(1-7) potentiates the hypotensive effect of bradykinin in vivo and prostaglandins may participate in the mechanism of potentiation by Ang-(1-7).

There are other potentially cardioprotective effects of Ang-(1-7) shown in animal studies.

1.3. Aims and Objectives. The objective of this systematic review will be to discuss human studies on the beneficial effects of angiotensin-(1-7) focusing on patients with heart failure.

\section{Methods}

2.1. Search Strategy of the Systematic Review. Highly sensitive search strategies were developed using appropriate subject headings and text word terms. The following electronic databases were searched: Pubmed, Embase, and Cochrane. In addition, conference proceedings and reference lists of all included studies were scanned to identify additionally potentially relevant studies. There were no start year restrictions, but the studies examined were restricted to English language reports.

2.2. Data Extraction. Two reviewers screened the titles (and abstracts if available) of all reports identified by the search strategy. Full copies of potentially relevant reports were obtained, studied, and assessed for inclusion. Data was discussed with the senior author, and disagreements were resolved by consensus.

\section{Results}

Figure 1 helps the reader appreciate the close relationship between Angiotensin-(1-7) and Angiotensin II. Figure 2 summarises the types of studies considered in the review.

\subsection{Studies on Human Heart Failure Patients. See Table 1.}

\subsection{Studies on Non-Heart-Failure Patients. See Table 2.}

\section{Discussion}

The main finding of this systematic review is that Ang-(1-7) plays an important cardioprotective role in heart failure in animals and in patients without heart failure. However, to date, the evidence for the role of Ang-(1-7) in human heart failure is limited (Table 1), whilst there are many more studies in non-heart-failure patients (Table 2).

The only study which evaluated the effects of Ang-(1-7) on patients with heart failure examined only 8 patients. These patients were all treated with an ACE inhibitor. The interaction of Ang-(1-7) with bradykinin was elegantly studied [31]. Ang-(1-7) did not have any significant effect on the pulse rate, blood pressure, or forearm blood flow in the noninfused arm during infusion of the peptide. Slight vasoconstriction was observed during Ang-(1-7) infusion at $500 \mathrm{pmol} / \mathrm{min}$ and $5000 \mathrm{pmol} / \mathrm{min}$; however, this was not statistically significant, and the absolute magnitude of the effect was very small. Importantly, no effect was observed with lower or higher doses. When Ang-(1-7) was coinfused with BK, the results were very similar to the initial infusion of BK alone. Interestingly, it showed a slight reduction in response to BK, though this was not statistically significant. Thus, intriguingly, the results from this study [31] are contradictory to the wealth of evidence gained from animal studies. Nevertheless, the findings were similar to another small study conducted on 8 non-heart-failure subjects [19]. Another study also found that if Ang-(1-7) was administered above a certain concentration (dose), its actions were abolished [37].

It is important to bear in mind the species gap between humans and animals and also the differences in methodologies used in the studies (e.g., some animal studies studied the effect of Ang-(1-7) on coronary arteries and others looked at 


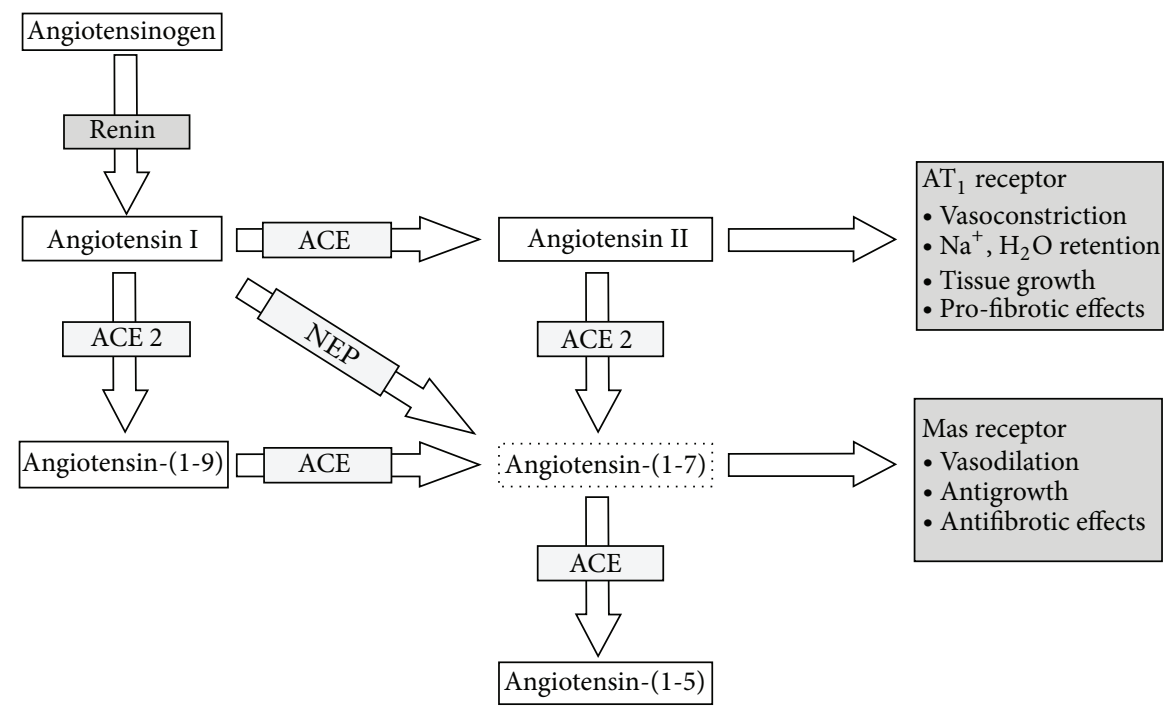

FIGURE 1: Demonstrating the relationship between Angiotensin I, Angiotensin II, Ang-(1-7), and the converting enzymes (ACE and ACE2).

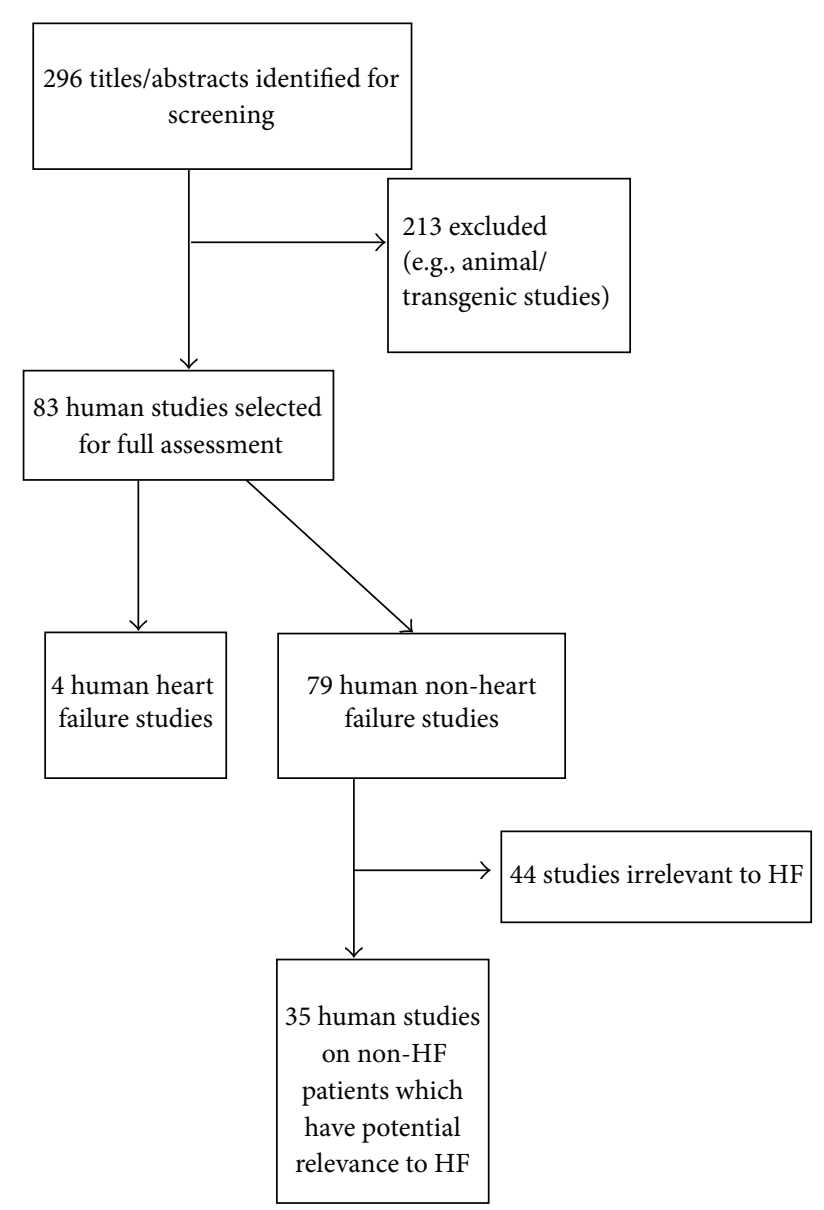

FIGURE 2: Flow of studies through the review.

mesenteric arteries). It seems that Ang-(1-7) is biologically inactive, in keeping with a study by Kono et al. [62] who also reported biological inactivity. If anything, its effects appear to have opposite actions (albeit nonsignificantly) to what is generally believed, a vasodilating, antiproliferative, and counterregulatory peptide. This lack of effect of Ang-(1-7) on haemodynamics is intriguing. It should be noted that the study had a relatively small sample size: 8 patients with chronic heart failure secondary to left ventricular dysfunction were recruited. The study could be underpowered statistically. All the patients in the study were already taking ACE inhibitors; therefore, the effect of Ang-(1-7) potentiating BK may have been obscured.

On the other hand, Ang-(1-7) attenuates vasoconstriction and increases blood flow in some studies, involving a larger number of patients, across different vascular beds, including the forearm and internal mammary artery [18, 32, 34, 44]. Thus, there are human studies demonstrating that the vasodilating property Ang-(1-7) is believed to hold. Ueda et al. [18] provided evidence of Ang-(1-7)'s action of attenuating vasoconstriction by Ang II in a dose-dependent manner. Sasaki et al. [63] supported this observation of vasodilation. The findings from Roks et al. [34] and Ueda et al. [44] were also consistent with the detection of a vasodilatory effect of Ang-(1-7). Reference [34] had a study population of 25 patients undergoing CABG (one did not have CABG), and here, Ang-(1-7) was found to behave like an ACE inhibitor. The blockade of vasoconstriction in this study could be due to many mechanisms which include the counterregulation of Ang II signalling [36] and the inhibition of ACE. Reference [44] involved a double-blind crossover design, allowing less room for bias. Coinfusion of Ang-(1-7) at $1000 \mathrm{pmol} / \mathrm{min}$ with BK significantly shifted the dose-response curve to the left; this was not the case at 100 and $10 \mathrm{pmol} / \mathrm{min}$ (additional analysis was performed to take into account the possible tachyphylaxis of BK in the study, which then found Ang(1-7) at $100 \mathrm{pmol} / \mathrm{min}$ to show effect). Ang-(1-7) seems to operate within a specified range according to a few human studies so far [31, 37, 44, 63]. Wilsdorf et al. [19] result of Ang-(1-7) having no significant effect on BK may have been due to fact that Wilsdorf et al. did not take into account tachyphylaxis in the data; therefore, the effect of 
TABLE 1: Studies on human heart failure patients.

\begin{tabular}{|c|c|c|c|c|}
\hline Study & $\begin{array}{l}\text { Full publi- } \\
\text { cation or } \\
\text { abstract }\end{array}$ & $\mathrm{N}$ & Endpoint & Key findings \\
\hline $\begin{array}{l}\text { Davie and } \\
\text { McMurray } \\
{[31]}\end{array}$ & Full & 8 & $\begin{array}{l}\text { Blood pressure, forearm blood } \\
\text { flow }(\mathrm{FBF})\end{array}$ & Ang-(1-7) has no significant effect on the endpoints. \\
\hline $\begin{array}{l}\text { Zisman et } \\
\text { al. [12] }\end{array}$ & Full & 22 & Ang-(1-7) forming activity & Ang-(1-7) forming activity is increased in failing heart. \\
\hline $\begin{array}{l}\text { Campbell } \\
\text { et al. [13] }\end{array}$ & Full & 9 & $\begin{array}{l}\text { Ang-(1-7) levels in arterial and } \\
\text { coronary sinus blood }\end{array}$ & $\begin{array}{l}\text { 39- and 22-fold increase of Ang-(1-7) levels in the } \\
\text { coronary sinus and arterial blood, respectively (patients } \\
\text { were receiving ACE inhibitor therapy). } \\
\text { A parallel increase in Ang-(1-7) and Ang I levels was } \\
\text { observed in HF patients on ACE inhibitors. } \\
\text { A 7.5- and 2.25-fold increase in the Ang-(1-7)/Ang II } \\
\text { ratio was associated with ACE inhibition in the } \\
\text { coronary sinus and arterial blood, respectively. }\end{array}$ \\
\hline $\begin{array}{l}\text { Batlle } \\
\text { Perales et } \\
\text { al. [32] }\end{array}$ & Abstract & $\begin{array}{c}33 \\
\text { (end-stage } \\
\text { HF); } \\
11 \text { (control) }\end{array}$ & & $\begin{array}{l}\text { Increased Mas receptor expression within } \\
\text { myocardiums in the remodelling stage (as suggested by } \\
\text { MMP3 and collagen I). Ang-(1-7) is therefore suggested } \\
\text { to have a role in the remodelling process. }\end{array}$ \\
\hline
\end{tabular}

Ang-(1-7) may have been masked by this possible phenomenon. References $[44,65]$ both found tachyphylactic responses to BK. Moreover, Wilsdorf and colleagues [19] did not analyse and measure greater doses of Ang-(1-7), which [44] did and found a significant effect.

Other studies about Ang-(1-7) in human heart failure have provided important insight into its role and suggested mechanisms, whereby it might be further exploited as a peptide with cardioprotective therapeutic benefits. Zisman et al. [12] validated a potential role for Ang-(1-7) in the human failing heart in an elegant study involving explanted hearts. This study involved 22 patients with heart failure due to either end-stage idiopathic cardiomyopathy (IDC) or primary pulmonary hypertension ( $\mathrm{PPH})$, compared with 13 patients with normal left ventricles (LV) on echocardiography prior to organ donation, which eventually sadly could not take place due to $\mathrm{ABO}$ blood type or donor/recipient size mismatch. In the transplanted hearts, Ang-(1-7) forming activity was significantly increased in the IDC left ventricle; the forming activity was greater for Ang II as a substrate than that for Ang I. Furthermore, the forming activity was greater than 4-fold (Ang II as substrate) compared to the nonfailing left ventricle. Ang II as a substrate for Ang-(1-7) appears to have activity in more areas of the heart than for Ang I, increasing the levels of Ang-(1-7) in both IDC ventricles and the $\mathrm{PPH}$ right ventricle. It should be remembered that the PPH left ventricle was not dysfunctional, which may explain the lack of increased Ang-(1-7) forming activity in the left ventricles of patients suffering from primary pulmonary hypertension. ACE inhibitor therapy did not significantly affect angiotensinase activity. Angiotensinase activity was higher in the failing hearts than the non-failing hearts. Zisman et al. [12] indicated a role for neutral endopeptidase and ACE2 in the formation of Ang-(1-7). The Ang-(1-7) forming activity was greater when Ang II was the substrate; moreover, the forming activity was identified in more areas of the heart, suggesting a major role for ACE2 in the failing heart.

Furthermore, few animal studies have shown that AT2 mediates antiproliferative and apoptotic signaling [66]. This has potentially beneficial consequences: it may positively influence the remodelling process known to be detrimental to cardiac function. However, it is unlikely that a direct relation between Ang-(1-7) and the AT2 receptor exists because it is not a natural ligand for it. It may be possible for there to be cross-talk between the Mas receptor and AT2 receptor. There is a strong correlation between Ang-(1-7) and Ang II, being efficiently converted, and the given evidence from previous studies in favour of Ang-(1-7) as a promising peptide to oppose Ang II effects suggests a potential counterregulatory role of Ang-(1-7) in the RAAS, thus being cardioprotective. This study has a few drawbacks; because of the method used to homogenise tissue, influential enzymes may have been lost, therefore unable to exert their effects on either Ang I or Ang II. Not only that, but also, as the authors were focusing on membrane-bound angiotensinases, they may have not identified the potential effects of the soluble ACE2. ACE2 gene expression was shown to be upregulated in the human failing heart in a study by Goulter et al. [67]. Putting the evidence from Zisman et al. [12], Goulter et al. [67], and Pan et al. [35] who declared positive influences by Ang-(17) on metalloproteinases (as a measure of myocardial fibrosis in the failing human heart) together, they showed Ang-(17) to be a promising physiological peptide in the failing human heart. In the postmyocardial infarction period, an increased matrix metalloproteinase (MMP)/tissue inhibitors of matrix metalloproteinases (TIMPs) ratio contributes to the remodelling stage [68]. Spinale et al. [69] and Schwartzkopff et al. [70] also reported changes in the MMP/TIMP ratio in the human failing heart.

Campbell et al. [13] have importantly provided evidence of Ang-(1-7)'s presence within the coronary sinus and arterial 


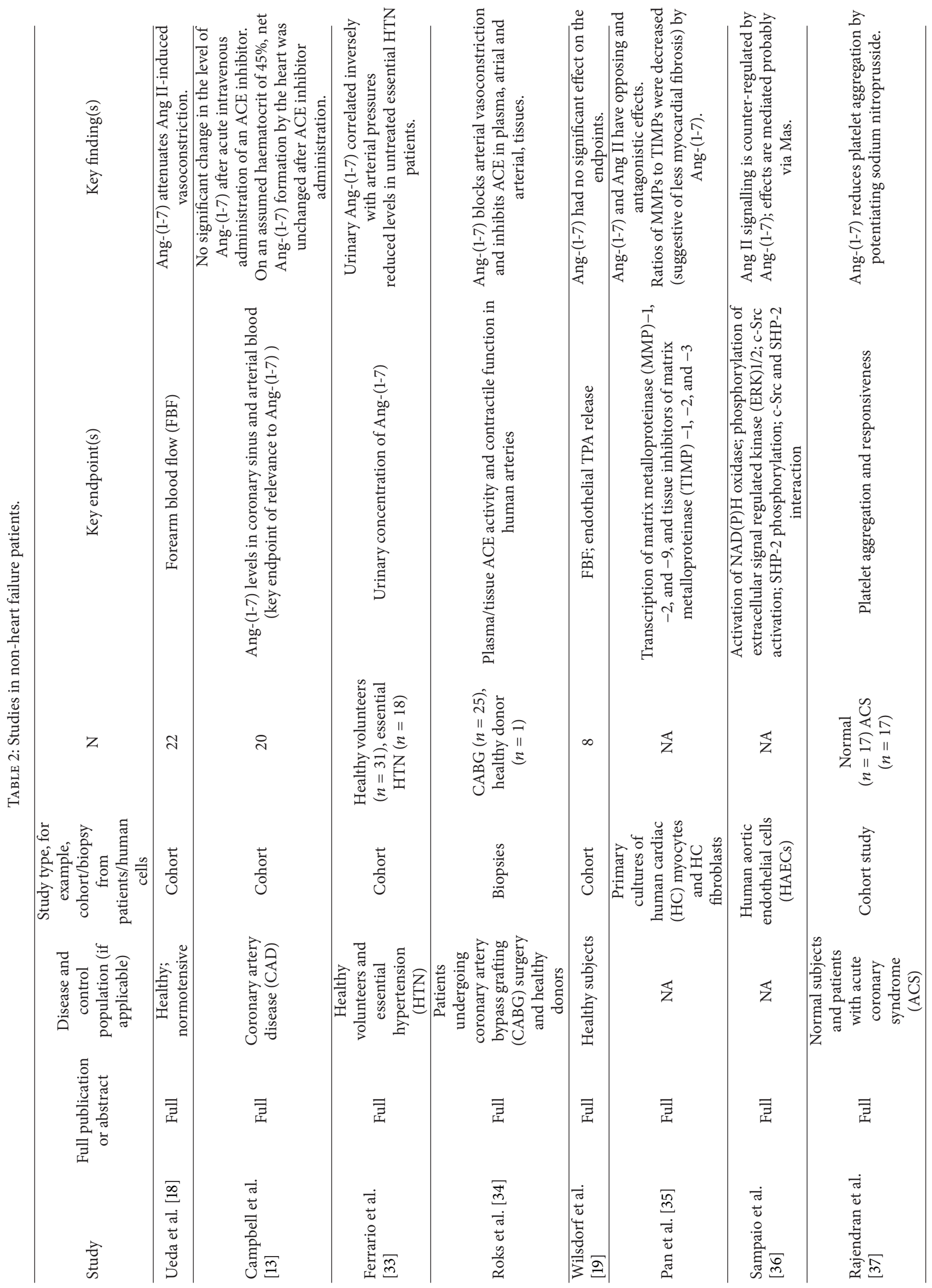




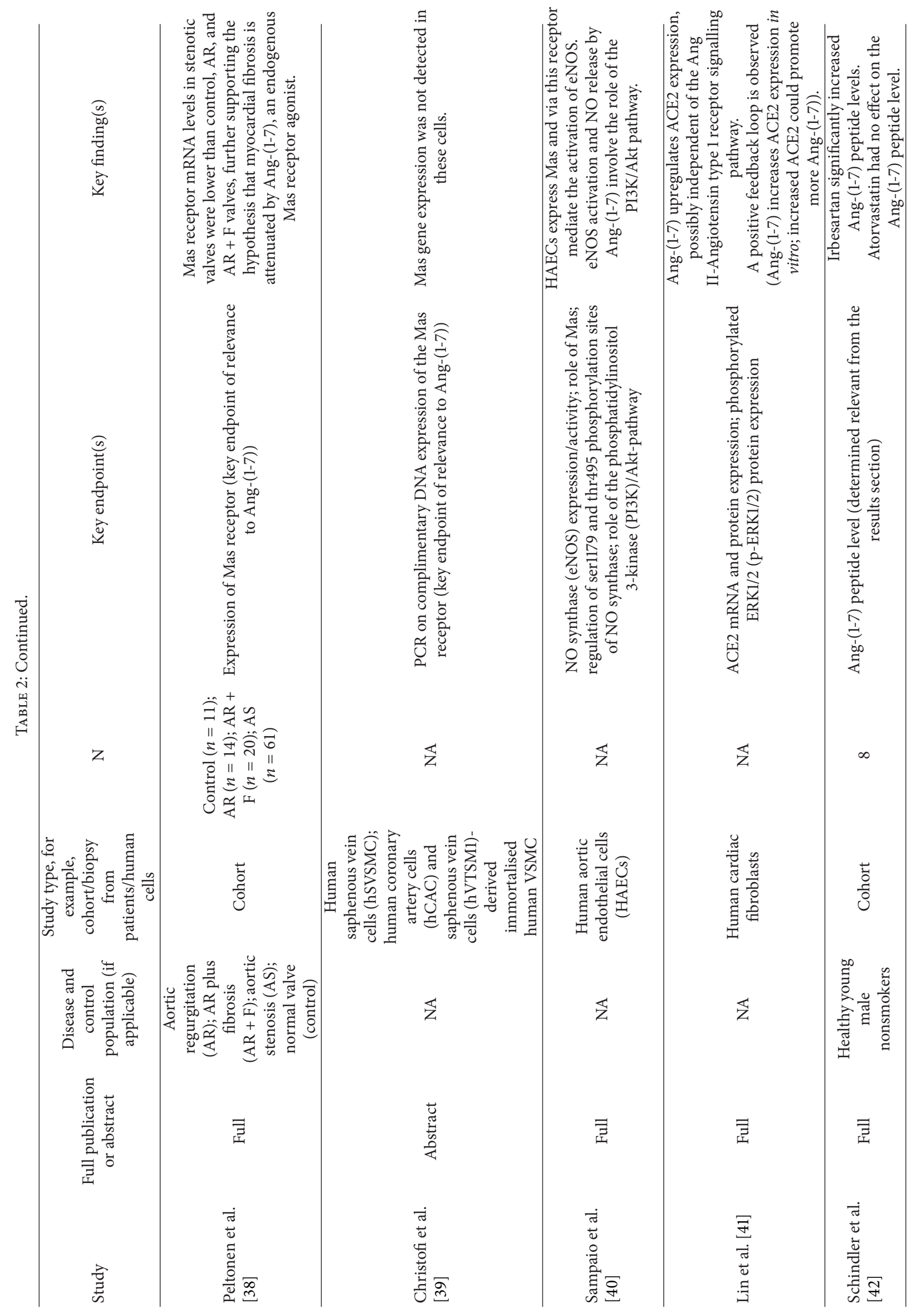




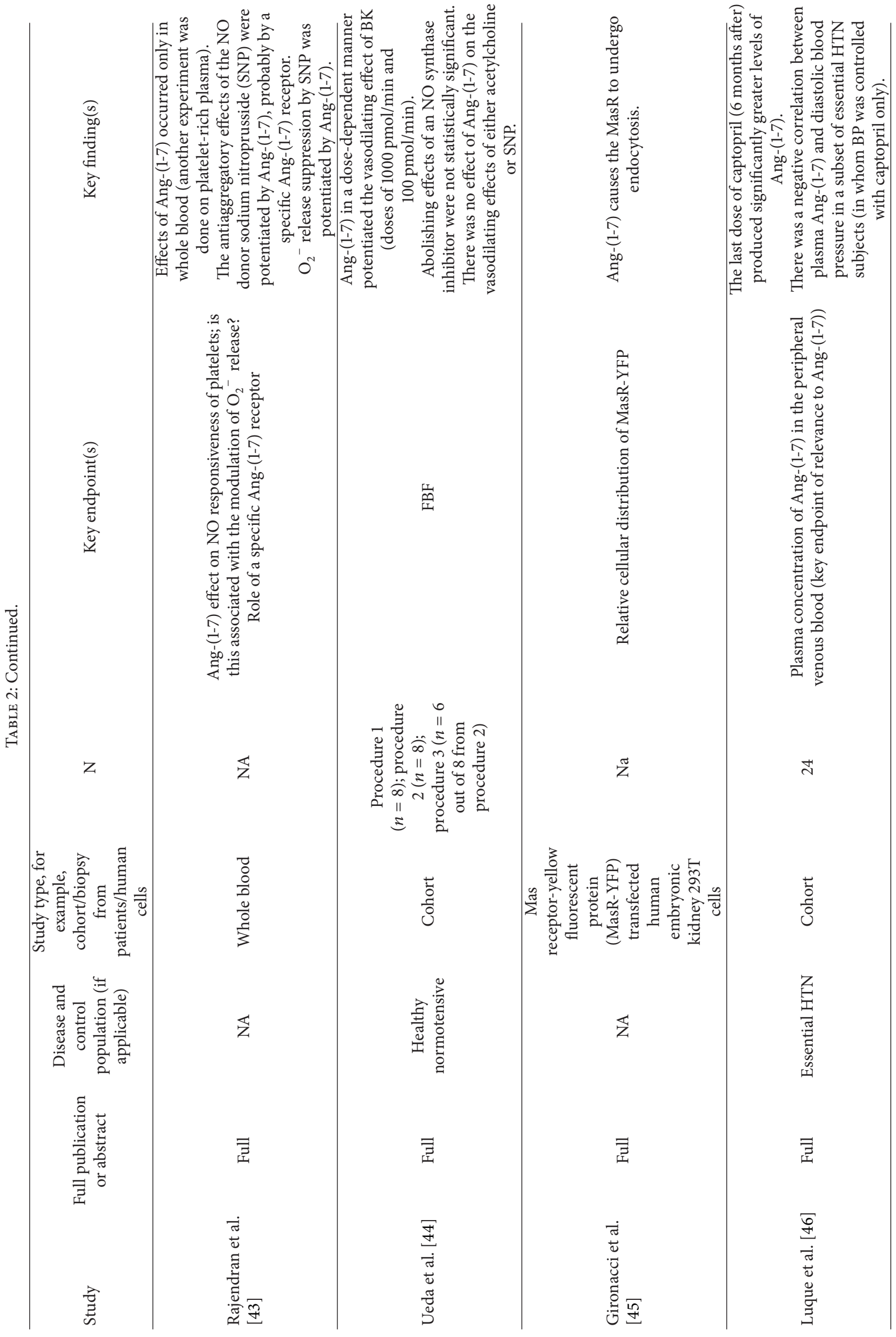




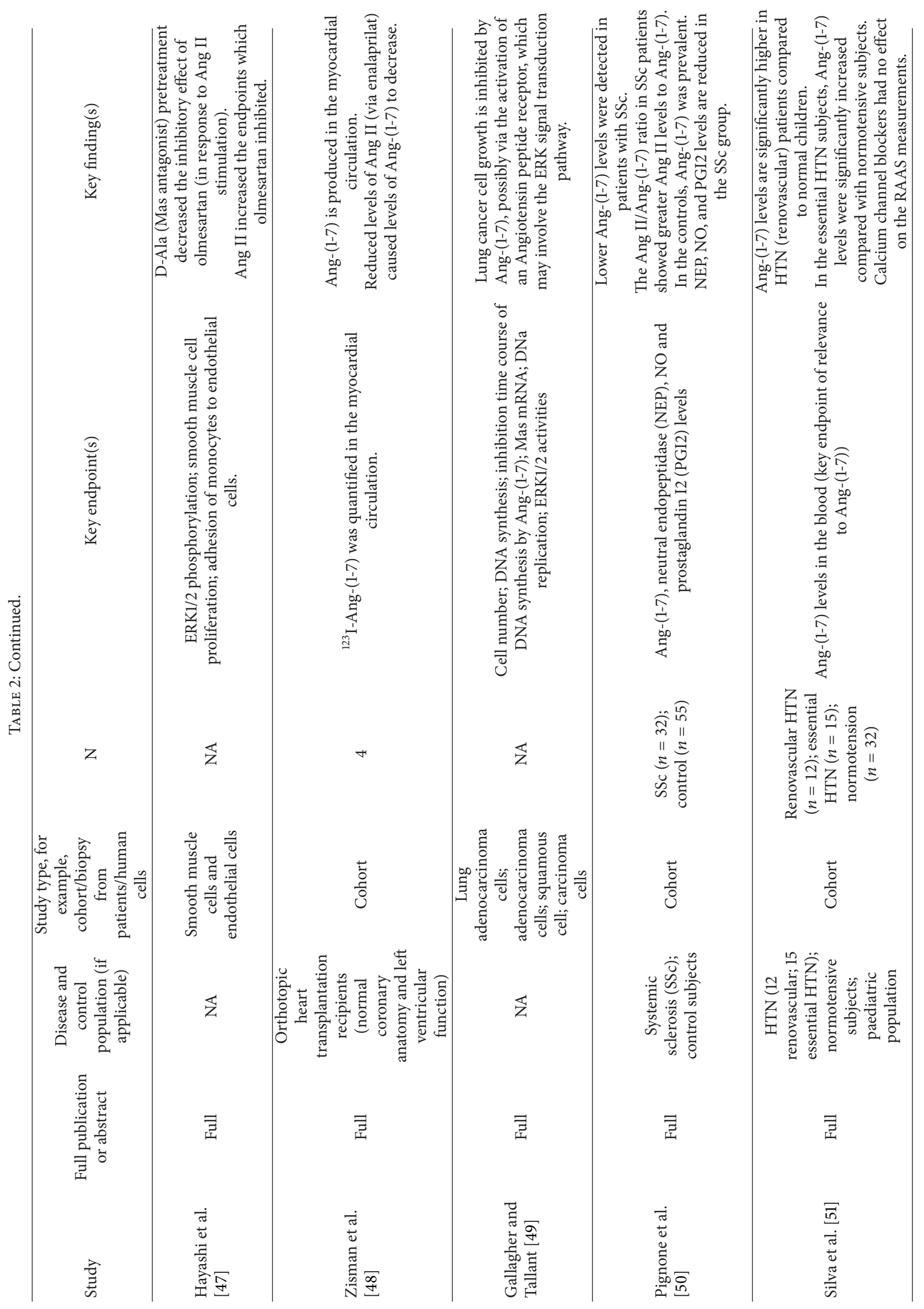




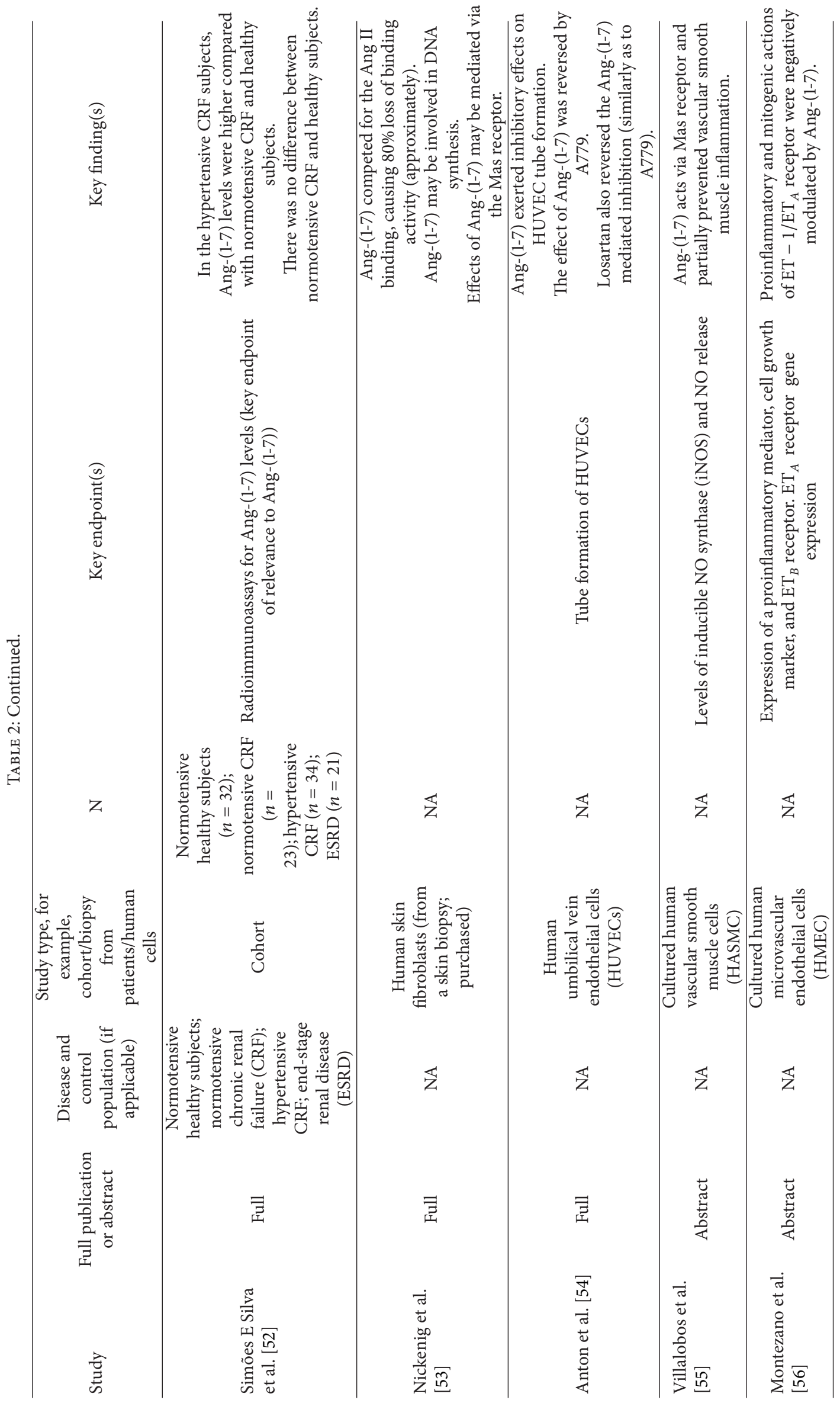




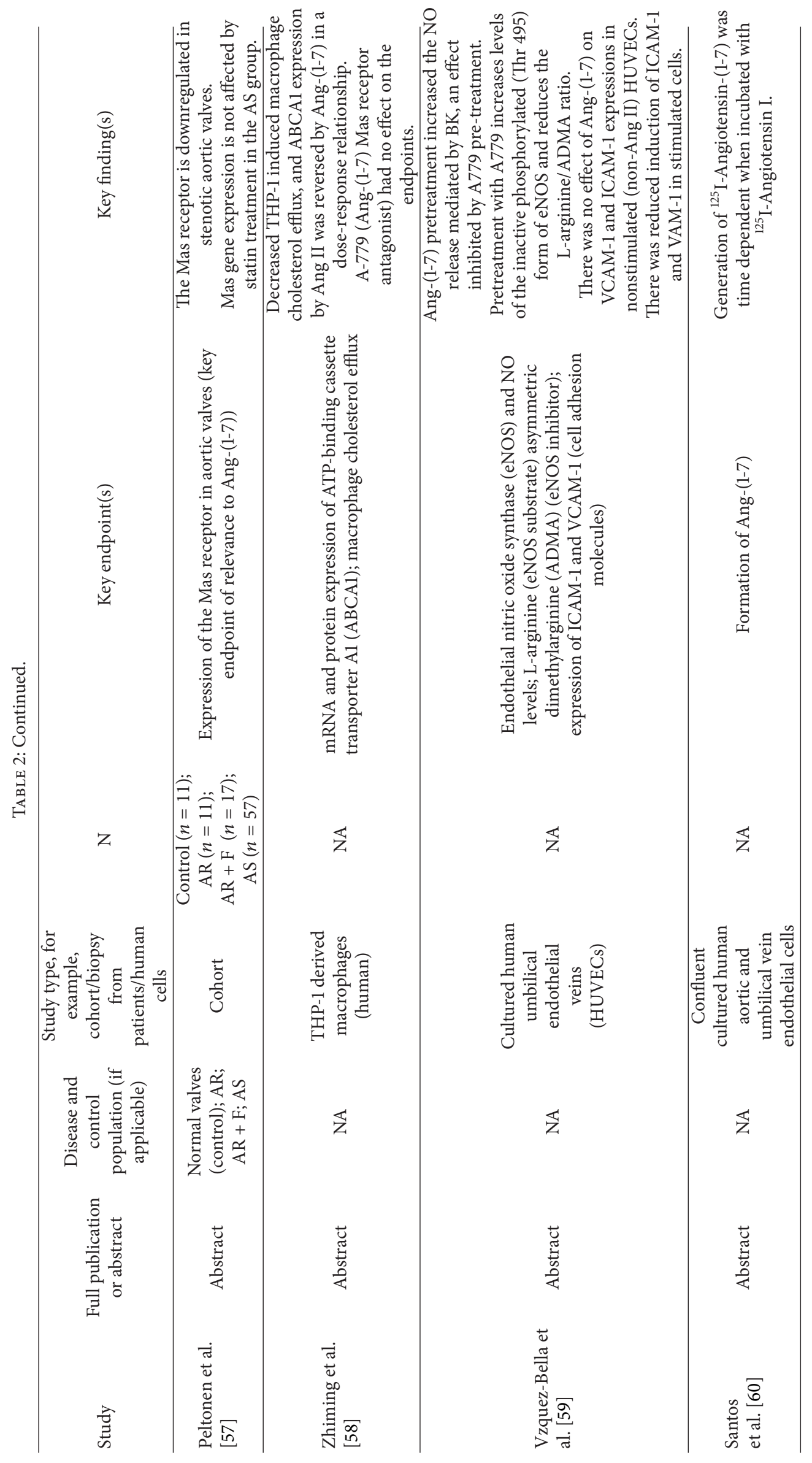




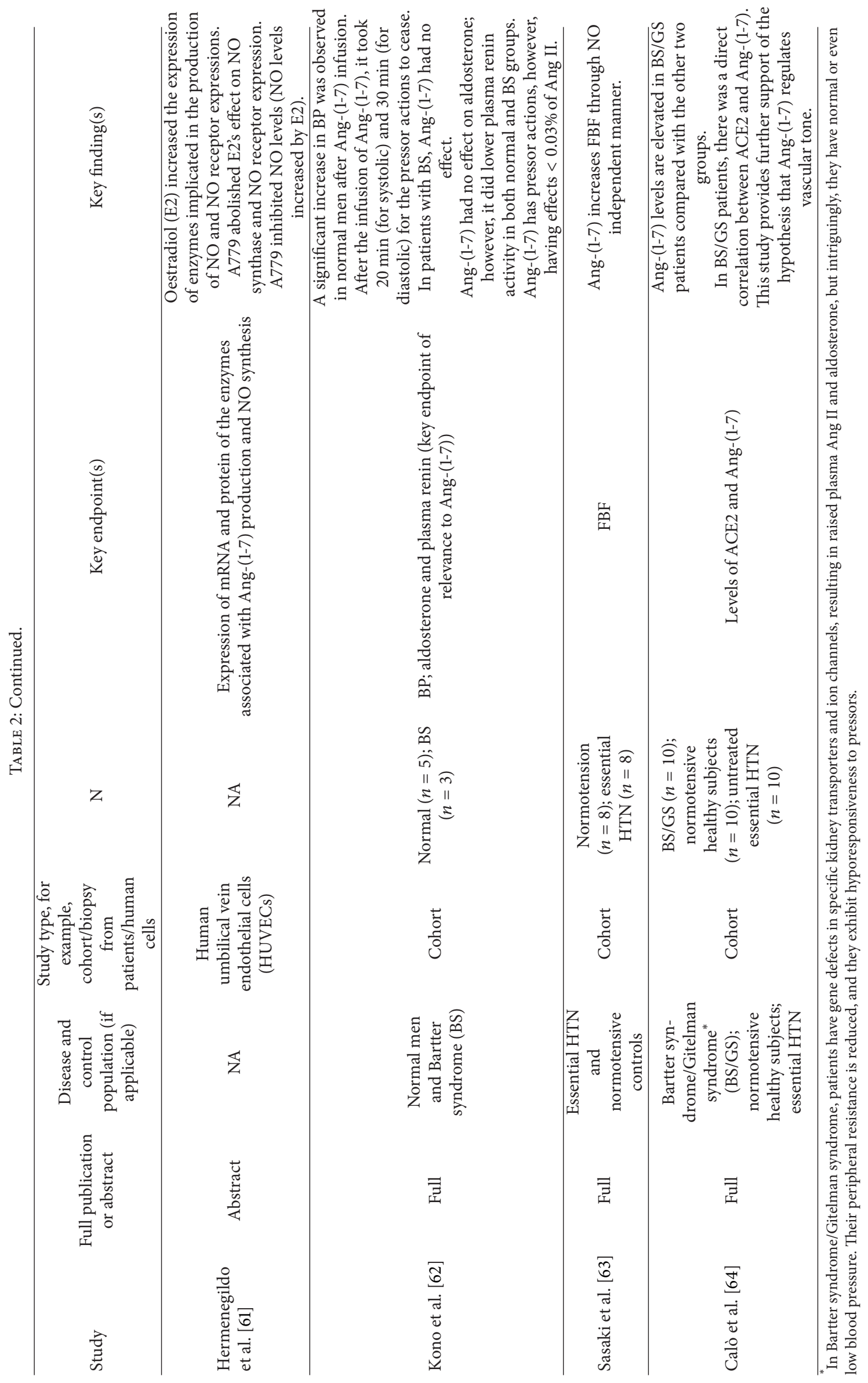


(radial) circulation of patients with heart failure taking ACE inhibitors. Here, an increased level of Ang-(1-7) was shown, by 39 - and 22 -fold in the coronary sinus and radial arterial blood, respectively, compared to non-heart-failure patients who were also not on ACE inhibitors. Ang-(1-7) appeared to rise in a parallel manner with Ang I levels. These are significant findings as ACE inhibitors now form the cornerstone of the management plan for heart failure. In patients treated with ACE inhibitors, angiotensin I goes up, leading to a rise in Ang-(1-7) via the NEP-like pathway. Thus, the NEP pathway is recognised as an alternate route for the production of Ang-(1-7) [12, 71]. When associated with ACE inhibition, the Ang-(1-7)/Ang II ratio has been found to be increased by 7.5- and 2.25-fold in the coronary sinus and arterial blood respectively. This provides further strong evidence in support of the role of the NEP-like pathway.

As discussed, Ang-(1-7) attenuates vasoconstriction and increases FBF in some studies [18, 34, 44, 63]. Further, Ang-(1-7) has anti-aggregatory effects [37, 43], opposes Ang II signalling in endothelial cells [36], and has beneficial effects against human atherosclerosis [58]. Therefore, finding it within the coronary sinus is highly regarded. However, Davie and McMurray [31] and Wilsdorf et al. [19] did not find any effect on the FBF in a small heart failure cohort and another small study of non-heart-failure patients. Campbell and colleagues [13] have presented data displaying a shift in the balance within the RAAS towards Ang-(1-7), increasing the physiological armoury against the deleterious effects of the ACE-Ang II-angiotensin subtype 1 receptor (AT1R) axis. Lin et al. [41] suggested a positive feedback loop where increased levels of Ang-(1-7) could increase the levels of ACE2 which would further increase Ang-(1-7). This was only shown in vitro. The common theme from these two studies along with Zisman et al. [12] is an increased level of Ang-(1-7). The study population of [13] was relatively small, involving 9 patients; however, this study has provided results proposing a beneficial cardioprotective role for Ang-(1-7) in heart failure. The study population was not homogeneous; moreover, there were a number of differences between the two groups, for instance, drug therapy. One possible explanation for the results in the study is that ACE inhibitor therapy can increase Ang-(1-7) levels [46].

Additionally, in 33 patients with end-stage HF undergoing heart transplant, as well as 11 controls, MAS17, MMP3, and collagen I mRNA expression were analysed in myocardial biopsies [32]. The patients were relatively young (mean age 54) but suffered severe left ventricular impairment (mean EF $21 \%$ ). Their left ventricles were significantly dilated (mean $7.2 \mathrm{~cm}$ ). Just over half had ischaemic heart failure, and 16 had nonischaemic aetiology. In this study, Perales et al. [32] demonstrated that the level of MMP3 and collagen I expressions was suggestive of the tissue being in the remodelling stage in a proportion of myocardium studied. Importantly, within the same subset of myocardium, there was an increased expression of the Mas receptor. As this receptor has been shown to mediate many actions of Ang II, it suggests a role for Ang-(1-7) in the remodelling process. Interestingly, in the small sample of hearts studied, there was no significant difference between patients with MMP3 expression regarding aetiology, severity of symptoms as measured by NYHA class, medication, or left ventricular dilation, although the abstract (which is as yet unpublished in full) did not specify whether there was any significant effect of ejection fraction on MMP3 expression.

\section{Clinical Implications and Future Research}

Heart failure (HF) is a common condition associated with significant morbidity and mortality despite major advances in medical, revascularization, and modern cardiac resynchronisation therapy (CRT)/implantable defibrillator (ICD) devices [72]. In 2006, more than 400,000 hospitalisations were recognised as due to or complicated by HF, accounting for about 4 million NHS hospital bed-days annually. The UK national HF audit for $2008 / 2009$ showed that $26 \%$ of patients aged $<75$ years and $56 \%$ of those aged $>75$ years would be dead within a year.

Stem cell therapy is the subject of many substantial research programmes. An alternative approach is to stimulate progenitor cells and vascular proliferation. Angiotensin (Ang)-(1-7) is an endogenous ligand for the G proteincoupled receptor Mas [11], which has a pivotal role in preserving normal endothelium-dependent relaxation [73]. Ang-(17) infusion stimulated proliferation of endothelial progenitor cells isolated from rodents. The theoretical beneficial effects of Ang-(1-7) in animal research on endothelial progenitor cells need to be further tested in humans. Human studies already suggest that Ang-(1-7) attenuates vasoconstriction, increases FBF in non-heart-failure patients, and opposes Ang II signalling in endothelial cells.

Importantly, Professor Walther's team has also found that infusion of Ang-(1-7) after MI in an animal model increased the number of c-Kit- and vascular endothelial growth factorpositive cells in infarcted hearts, inhibited cardiac hypertrophy, and improved cardiac function [74]. Furthermore, the nonpeptidic Ang-(1-7) receptor agonist AVE0991 also improved cardiac contractility in diabetic rats [75]. In addition, Ang (1-7) stimulates haematopoietic progenitor cells in vitro and in vivo [76]. Ang-(1-7) has already been studied in phase I/II trials in patients with solid tumours $[77,78]$. Daily subcutaneous doses of 2.5-100 micrograms/kg/day were safe and well tolerated. Thus, Ang-(1-7) is a candidate molecule that has already been administered to patients with breast cancer undergoing chemotherapy to correct anaemia (a common comorbidity in HF). In a small study of 8 patients with chronic HF, Ang (1-7) had no significant effect on blood pressure (BP) and caused no adverse effects [31]. Absence of a vasodilator response in patients who are already on ACE inhibitors might be explained at least in part by the fact that the peptide Ang-(1-7) is metabolised by ACE. There is growing evidence to suggest that the beneficial effects of ACE inhibitors and angiotensin receptor blockers (ARBs) are at least in part mediated via Ang-(1-7).

In addition, chronic angiotensin-(1-7) selectively prevents cardiac fibrosis in the DOCA-salt model of hypertension, without any effect on blood pressure or cardiac hypertrophy [79]. Further support of the role of Ang-(1-7) in helping 
myocardial fibrosis came from observation by Raizada's team that the antifibrotic effect of an ACE2 activator correlated with increased cardiac Ang-(1-7) immunostaining [80]. Metalloproteinases and TIMPs appear to have an important role in myocardial fibrosis and cardiac dysfunction in HF. Pan et al. [35] demonstrated how Ang-(1-7) decreased ratios of MMPs to TIMPs in human cardiac cells. A study performed on patients with heart failure examining the effects of Ang(1-7) on the expression of MMPs and TIMPs will prove beneficial. The ratios of these enzymes are altered to some degree in HF $[69,70]$. This may show direct effects of Ang(1-7) on the remodelling process known to be detrimental to the failing myocardium.

To follow on from Davie and McMurray [31], it would be worthwhile to recruit a much larger sample size to test the hypothesis that Ang-(1-7) has beneficial effects on haemodynamics in human heart failure.

Other cardioprotective effects that were demonstrated in animal studies might be translated into humans. We are planning to conduct a randomised controlled trial to test the hypotheses that Ang-(1-7) might improve cardiac hypertrophy and function.

Investigating the expression of Mas-gene mRNA or Masreceptor distribution throughout the human failing heart will provide good insight into activity of Ang-(1-7). Furthermore, the study can also check if there is a correlation between expression and stage of $\mathrm{HF}$ and the remodelling process, ventricular size, and ejection fraction.

The nonpeptidic Ang (1-7) receptor agonist AVE0991 has already been shown to improve cardiac contractility in diabetic rats. Development of an oral nonpeptidic Ang (1-7) receptor agonist will enable us to perform a well-designed randomised controlled trial to study the cardioprotective effects of Ang-(1-7) in patients on ACE inhibitors or ARBs [81].

\section{Conclusions}

The main finding of this systematic review is that Ang-(1-7) plays an important cardioprotective role in heart failure in animals and in patients without heart failure. However, to date, the evidence for the role of Ang-(1-7) in human heart failure is limited. Nevertheless, accumulating evidence from a few studies demonstrated the importance of Ang-(1-7) as a potential therapeutic agent in heart failure.

\section{References}

[1] D. Lloyd-Jones, R. J. Adams, T. M. Brown et al., "Executive summary: heart disease and stroke statistics-2010 update: a report from the american heart association," Circulation, vol. 121, no. 7, pp. e46-e215, 2010.

[2] T. X. Dallas and American Heart Association, Heart Disease and Stroke Statistics 2008 Update, American Heart Association, Chicago, Ill, USA, 2008.

[3] P. A. McCullough, E. F. Philbin, J. A. Spertus, S. Kaatz, K. R. Sandberg, and W. D. Weaver, "Confirmation of a heart failure epidemic: findings from the resource utilization among congestive heart failure (REACH) study,' Journal of the American College of Cardiology, vol. 39, no. 1, pp. 60-69, 2002.

[4] J. B. Croft, W. H. Giles, R. A. Pollard, N. L. Keenan, M. L. Casper, and R. F. Anda, "Heart failure survival among older adults in the United States: a poor prognosis for an emerging epidemic in the Medicare population," Archives of Internal Medicine, vol. 159, no. 5, pp. 505-510, 1999.

[5] Centers for Medicare and Medicaid Services, Health Care Financing Review: Medicare and Medicaid Statistical Supplement, Table 5. 5: Discharges, Total Days of Care, and Program Payments for Medicare Beneficiaries Discharged from ShortStay Hospitals, by Principal Diagnoses Within Major Diagnostic Classifications (MDCs): Calendar Year 2006, Centers for Medicare and Medicaid Services, Baltimore, Md, USA, 2005, http://www.cms.hhs.gov/MedicareMedicaid StatSupp/.

[6] D. Levy, S. Kenchaiah, M. Glarson et al., "Long-term trends in the incidence of and survival with heart failure," New England Journal of Medicine, vol. 347, no. 18, pp. 1397-1402, 2002.

[7] S. M. Dunlay, M. M. Redfield, S. A. Weston et al., "Hospitalizations after heart failure diagnosis. A community perspective," Journal of the American College of Cardiology, vol. 54, no. 18, pp. 1695-1702, 2009.

[8] R. J. Goldberg, J. Ciampa, D. Lessard, T. E. Meyer, and F. A. Spencer, "Long-term survival after heart failure: a contemporary population-based perspective," Archives of Internal Medicine, vol. 167, no. 5, pp. 490-496, 2007.

[9] C. M. Ferrario and S. N. Iyer, "Angiotensin-(1-7): a bioactive fragment of the renin-angiotensin system," Regulatory Peptides, vol. 78, no. 1-3, pp. 13-18, 1998.

[10] C. M. Ferrario, "Angiotensin-(1-7) and antihypertensive mechanisms," Journal of Nephrology, vol. 11, no. 6, pp. 278-283, 1998.

[11] R. A. S. Santos, A. C. Simoes e Silva, C. Maric et al., "Angiotensin-(1-7) is an endogenous ligand for the G proteincoupled receptor Mas," Proceedings of the National Academy of Sciences of the United States of America, vol. 100, no. 14, pp. 8258-8263, 2003.

[12] L. S. Zisman, R. S. Keller, B. Weaver et al., "Increased angiotensin-(1-7)-forming activity in failing human heart ventricles: evidence for upregulation of the angiotensin-converting enzyme homologue ACE2," Circulation, vol. 108, no. 14, pp. 1707-1712, 2003.

[13] D. J. Campbell, C. J. Zeitz, M. D. Esler, and J. D. Horowitz, "Evidence against a major role for angiotensin converting enzyme-related carboxypeptidase (ACE2) in angiotensin peptide metabolism in the human coronary circulation," Journal of Hypertension, vol. 22, no. 10, pp. 1971-1976, 2004.

[14] S. Keidar, M. Kaplan, and A. Gamliel-Lazarovich, "ACE2 of the heart: from angiotensin I to angiotensin (1-7)," Cardiovascular Research, vol. 73, no. 3, pp. 463-469, 2007.

[15] C. M. Ferrario, M. C. Chappell, E. A. Tallant, K. B. Brosnihan, and D. I. Diz, "Counterregulatory actions of angiotensin-(1-7)," Hypertension, vol. 30, no. 3, pp. 535-541, 1997.

[16] L. A. Calò, S. Schiavo, P. A. Davis et al., "ACE2 and angiotensin 1-7 are increased in a human model of cardiovascular hyporeactivity: pathophysiological implications," Journal of Nephrology, vol. 23, no. 4, pp. 472-477, 2010.

[17] C. Mercure, A. Yogi, G. E. Callera et al., "Angiotensin(1-7) blunts hypertensive cardiac remodeling by a direct effect on the heart," Circulation Research, vol. 103, no. 11, pp. 1319-1326, 2008.

[18] S. Ueda, S. Masumori-Maemoto, K. Ashino et al., "Angiotensin(1-7) attenuates vasoconstriction evoked by angiotensin II but 
not by noradrenaline in man," Hypertension, vol. 35, no. 4, pp. 998-1001, 2000.

[19] T. Wilsdorf, J. V. Gainer, L. J. Murphey, D. E. Vaughan, and N. J. Brown, "Angiotensin-(1-7) does not affect vasodilator or TPA responses to bradykinin in human forearm," Hypertension, vol. 37, no. 4, pp. 1136-1140, 2001.

[20] M. T. Schiavone, R. A. S. Santos, K. B. Brosnihan, M. C. Khosla, and C. M. Ferrario, "Release of vasopressin from the rat hypothalamo-neurohypophysial system by angiotensin-(1-7) heptapeptide," Proceedings of the National Academy of Sciences of the United States of America, vol. 85, no. 11, pp. 4095-4098, 1988.

[21] R. A. S. Santos, M. J. Campagnole-Santos, and S. P. Andrade, "Angiotensin-(1-7): an update," Regulatory Peptides, vol. 91, no. 1-3, pp. 45-62, 2000.

[22] H. Heitsch, S. Brovkovych, T. Malinski, and G. Wiemer, "Angiotensin-(1-7)-stimulated nitric oxide and superoxide release from endothelial cells," Hypertension, vol. 37, no. 1, pp. 72-76, 2001.

[23] P. Li, M. C. Chappell, C. M. Ferrario, and K. B. Brosnihan, "Angiotensin-(1-7) augments bradykinin-induced vasodilation by competing with ACE and releasing nitric oxide," Hypertension, vol. 29, no. 1, pp. 394-400, 1997.

[24] G. J. Trachte, K. Meixner, C. M. Ferrario, and M. C. Khosla, "Prostaglandin production in response to angiotensin-(1-7) in rabbit isolated vasa deferentia," Prostaglandins, vol. 39, no. 4, pp. 385-394, 1990.

[25] N. Jaiswal, E. A. Tallant, D. I. Diz, M. C. Khosla, and C. M. Ferrario, "Subtype 2 angiotensin receptors mediate prostaglandin synthesis in human astrocytes," Hypertension, vol. 17, no. 6, pp. 1115-1120, 1991.

[26] K. B. Brosnihan, P. Li, and C. M. Ferrario, "Angiotensin-(17) dilates canine coronary arteries through kinins and nitric oxide," Hypertension, vol. 27, no. 3, pp. 523-528, 1996.

[27] I. Porsti, A. T. Bara, R. Busse, and M. Hecker, "Release of nitric oxide by angiotensin-(1-7) from porcine coronary endothelium: implications for a novel angiotensin receptor," British Journal of Pharmacology, vol. 111, no. 3, pp. 652-654, 1994.

[28] I. F. Benter, C. M. Ferrario, M. Morris, and D. I. Diz, "Antihypertensive actions of angiotensin-(1-7) in spontaneously hypertensive rats," American Journal of Physiology, vol. 269, no. 1, part 2, pp. H313-H319, 1995.

[29] L. Fernandes, Z. B. Fortes, D. Nigro, R. C. A. Tostes, R. A. S. Santos, and M. H. Catelli de Carvalho, "Potentiation of bradykinin by angiotensin-(1-7) on arterioles of spontaneously hypertensive rats studied in vivo," Hypertension, vol. 37 , no. 2 , part 2, pp. 703-709, 2001.

[30] R. D. Paula, C. V. Lima, M. C. Khosla, and R. A. S. Santos, "Angiotensin-(1-7) potentiates the hypotensive effect of bradykinin in conscious rats," Hypertension, vol. 26, no. 6, part 2, pp. 1154-1159, 1995.

[31] A. P. Davie and J. J. V. McMurray, "Effect of angiotensin-(1-7) and bradykinin in patients with heart failure treated with an ACE inhibitor," Hypertension, vol. 34, no. 3, pp. 457-460, 1999.

[32] M. Batlle Perales, F. Perez-Villa, A. Lazaro et al., "The Ang(1-7) mas receptor expression is increased in myocardial tissue from heart failure patients that are in a highly active remodelling stage," European Journal of Heart Failure, vol. 8, p. ii813, 2009.

[33] C. M. Ferrario, N. Martell, C. Yunis et al., "Characterization of angeotensin-(1-7) in the urine of normal and essential hypertensive subjects," American Journal of Hypertension, vol. 11, no. 2, pp. 137-146, 1998.
[34] A. J. M. Roks, P. P. Van Geel, Y. M. Pinto et al., "Angiotensin(1-7) is a modulator of the human renin-angiotensin system," Hypertension, vol. 34, no. 2, pp. 296-301, 1999.

[35] C. Pan, C. Wen, and C. Lin, "Interplay of angiotensin II and angiotensin(1-7) in the regulation of matrix metalloproteinases of human cardiocytes," Experimental Physiology, vol. 93, no. 5, pp. 599-612, 2008.

[36] W. O. Sampaio, C. H. De Castro, R. A. S. Santos, E. L. Schiffrin, and R. M. Touyz, "Angiotensin-(1-7) counterregulates angiotensin II signaling in human endothelial cells," Hypertension, vol. 50, no. 6, pp. 1093-1098, 2007.

[37] S. Rajendran, Y. Y. Chirkov, D. J. Campbell, and J. D. Horowitz, "Angiotensin-(1-7) enhances anti-aggregatory effects of the nitric oxide donor sodium nitroprusside," Journal of Cardiovascular Pharmacology, vol. 46, no. 4, pp. 459-463, 2005.

[38] T. Peltonen, J. Näpänkangas, P. Ohtonen et al., “(Pro)renin receptors and angiotensin converting enzyme 2/angiotensin-(17)/Mas receptor axis in human aortic valve stenosis," Atherosclerosis, vol. 216, no. 1, pp. 35-43, 2011.

[39] F. Christofi, S. Wijetunge, P. S. Sever, and A. D. Hughes, "Expression and function of the tissue-renin-angiotensin system in human vascular smooth muscle cells in culture," Cardiovascular Research, vol. 87, p. S60, 2010.

[40] W. O. Sampaio, R. A. S. Dos Santos, R. Faria-Silva, L. T. Da Mata Machado, E. L. Schiffrin, and R. M. Touyz, "Angiotensin-(1-7) through receptor Mas mediates endothelial nitric oxide synthase activation via Akt-dependent pathways," Hypertension, vol. 49, no. 1, pp. 185-192, 2007.

[41] C. Lin, C. Pan, C. Wen, T. Yang, and T. Kuan, "Regulation of angiotensin converting enzyme II by angiotensin peptides in human cardiofibroblasts," Peptides, vol. 31, no. 7, pp. 1334-1340, 2010.

[42] C. Schindler, K. B. Brosnihan, C. M. Ferrario et al., "Comparison of inhibitory effects of irbesartan and atorvastatin treatment on the renin angiotensin system (RAS) in veins: a randomized double-blind crossover trial in healthy subjects," Journal of Clinical Pharmacology, vol. 47, no. 1, pp. 112-120, 2007.

[43] S. Rajendran, Y. Y. Chirkov, and J. D. Horowitz, "Potentiation of platelet responsiveness to nitric oxide by angiotensin-(1-7) is associated with suppression of superoxide release," Platelets, vol. 18, no. 2, pp. 158-164, 2007.

[44] S. Ueda, S. Masumori-Maemoto, A. Wada, M. Ishii, K. B. Brosnihan, and S. Umemura, "Angiotensin(1-7) potentiates bradykinin-induced vasodilatation in man," Journal of Hypertension, vol. 19, no. 11, pp. 2001-2009, 2001.

[45] M. M. Gironacci, H. P. Adamo, G. Corradi, R. A. Santos, P. Ortiz, and O. A. Carretero, "Angiotensin (1-7) induces mas receptor internalization," Hypertension, vol. 58, no. 2, pp. 176-181, 2011.

[46] M. Luque, P. Martin, N. Martell, C. Fernandez, K. B. Brosnihan, and C. M. Ferrario, "Effects of captopril related to increased levels of prostacyclin and angiotensin-(1-7) in essential hypertension," Journal of Hypertension, vol. 14, no. 6, pp. 799-805, 1996.

[47] N. Hayashi, K. Yamamoto, M. Ohishi et al., "The counterregulating role of ACE2 and ACE2-mediated angiotensin 1-7 signaling against angiotensin II stimulation in vascular cells," Hypertension Research, vol. 33, no. 11, pp. 1182-1185, 2010.

[48] L. S. Zisman, G. E. Meixell, M. R. Bristow, and C. C. Canver, "Angiotensin-(1-7) formation in the intact human heart: in vivo dependence on angiotensin II as substrate," Circulation, vol. 108, no. 14, pp. 1679-1681, 2003. 
[49] P. E. Gallagher and E. A. Tallant, "Inhibition of human lung cancer cell growth by angiotensin-(1-7)," Carcinogenesis, vol. 25, no. 11, pp. 2045-2052, 2004.

[50] A. Pignone, A. Del Rosso, K. B. Brosnihan et al., "Reduced circulating levels of angiotensin-(1-7) in systemic sclerosis: a new pathway in the dysregulation of endothelial-dependent vascular tone control," Annals of the Rheumatic Diseases, vol. 66, no. 10, pp. 1305-1310, 2007.

[51] A. C. S. E. Silva, J. S. S. Diniz, A. Regueira Filho, and R. A. S. Santos, "The renin angiotensin system in childhood hypertension: selective increase of angiotensin-(1-7) in essential hypertension," Journal of Pediatrics, vol. 145, no. 1, pp. 93-98, 2004.

[52] A. C. Simões E Silva, J. S. S. Diniz, R. M. Pereira, S. V. B. Pinheiro, and R. A. S. Santos, "Circulating renin angiotensin system in childhood chronic renal failure: marked increase of angiotensin-(1-7) in end-stage renal disease," Pediatric Research, vol. 60, no. 6, pp. 734-739, 2006.

[53] G. Nickenig, G. Geisen, H. Vetter, and A. Sachinidis, "Characterization of angiotensin receptors on human skin fibroblasts," Journal of Molecular Medicine, vol. 75, no. 3, pp. 217-222, 1997.

[54] L. Anton, D. C. Merrill, L. A. A. Neves, and K. B. Brosnihan, "Angiotensin-(1-7) inhibits in vitro endothelial cell tube formation in human umbilical vein endothelial cells through the AT17 receptor," Endocrine, vol. 32, no. 2, pp. 212-218, 2007.

[55] L. Villalobos, T. Romacho, E. Cercas, E. Palacios, C. Sanchez Ferrer, and C. Peir, "The angiotensin-(1-7)/Mas receptor axis exhibits anti-inflammatory properties in human vascular smooth muscle cells," European Journal of Clinical Pharmacology, vol. 66, p. S40, 2010.

[56] A. C. Montezano, H. Yusuf, R. A. Santos, C. H. Castro, and R. M. Touyz, "Angiotensin 1-7 attenuates growth and inflammation induced by ET-1 in human endothelial cells-Crosstalk between mas and ETB receptors," Hypertension, vol. 56, no. 5, p. e144, 2010.

[57] T. Peltonen, J. Napankangas, P. Ohtonen et al., "Defining local renin-angiotensin system in human aortic valve stenosis: geneexpression of ACE2 and mas receptor in stenotic valves," Cardiology, vol. 115, no. 4, pp. 281-282, 2010.

[58] Y. Zhiming, "A study on effects of Ang II and Ang-(107) on cholesterol efflux in THP-1 human macrophages," Circulation, vol. 122, no. 2, p. e139, 2010.

[59] M. Vzquez-Bella, S. Valleja, V. Azcutia et al., "The role of the angiotensin-(1-7)/receptor Mas axis in endothelial dysfunction," Methods and Findings in Experimental and Clinical Pharmacology A, vol. 31, supplement 6, p. 140, 2009.

[60] R. A. S. Santos, K. B. Brosnihan, D. W. Jacobsen, P. E. DiCorleto, and C. M. Ferrario, "Production of angiotensin-(1-7) by human vascular endothelium," Hypertension, vol. 19, supplement 2, pp. II56-II61, 1992.

[61] C. Hermenegildo, A. Sobrino, E. Monsalve et al., "Angiotensin 1-7 mas receptor mediates nitric oxide production induced by estradiol in endothelial cells," European Journal of Clinical Pharmacology, vol. 66, p. S40, 2010.

[62] T. Kono, A. Taniguchi, and H. Imura, "Biological activities of angiotensin II-(1-6)-hexapeptide and angiotensin II-(1-7)heptapeptide in man," Life Sciences, vol. 38, no. 16, pp. 1515-1519, 1986.

[63] S. Sasaki, Y. Higashi, K. Nakagawa, H. Matsuura, G. Kajiyama, and T. Oshima, "Effects of angiotensin-(1-7) on forearm circulation in normotensive subjects and patients with essential hypertension," Hypertension, vol. 38, no. 1, pp. 90-94, 2001.
[64] L. A. Calò, S. Schiavo, P. A. Davis et al., "ACE2 and angiotensin 1-7 are increased in a human model of cardiovascular hyporeactivity: pathophysiological implications," Journal of Nephrology, vol. 23, no. 4, pp. 472-477, 2010.

[65] N. Benjamin, J. R. Cockcroft, J. G. Collier, C. T. Dollery, J. M. Ritter, and D. J. Webb, "Local inhibition of converting enzyme and vascular responses to angiotensin and bradykinin in the human forearm," Journal of Physiology, vol. 412, pp. 543-555, 1989.

[66] O. Von Bohlen und Halbach, T. Walther, M. Bader, and D. Albrecht, "Genetic deletion of angiotensin AT2 receptor leads to increased cell numbers in different brain structures of mice," Regulatory Peptides, vol. 99, no. 2-3, pp. 209-216, 2001.

[67] A. B. Goulter, M. J. Goddard, J. C. Allen, and K. L. Clark, "ACE2 gene expression is up-regulated in the human failing heart," BMC Medicine, vol. 2, p. 19, 2004.

[68] Y. Y. Li, A. M. Feldman, Y. Sun, and C. F. McTiernan, "Differential expression of tissue inhibitors of metalloproteinases in the failing human heart," Circulation, vol. 98, no. 17, pp. 1728-1734, 1998.

[69] F. G. Spinale, M. L. Coker, L. J. Heung et al., "A matrix metalloproteinase induction/activation system exists in the human left ventricular myocardium and is upregulated in heart failure," Circulation, vol. 102, no. 16, pp. 1944-1949, 2000.

[70] B. Schwartzkopff, M. Fassbach, B. Pelzer, M. Brehm, and B. E. Strauer, "Elevated serum markers of collagen degradation in patients with mild to moderate dilated cardiomyopathy," European Journal of Heart Failure, vol. 4, no. 4, pp. 439-444, 2002.

[71] K. Yamamoto, M. C. Chappell, K. B. Brosnihan, and C. M. Ferrario, "In vivo metabolism of angiotensin I by neutral endopeptidase (EC 3.4.24.11) in spontaneously hypertensive rats," Hypertension, vol. 19, supplement 6, pp. 692-696, 1992.

[72] J. G. F. Cleland, J. Daubert, E. Erdmann et al., "The effect of cardiac resynchronization on morbidity and mortality in heart failure," New England Journal of Medicine, vol. 352, no. 15, pp. 1539-1549, 2005.

[73] C. Peiró, S. Vallejo, F. Gembardt et al., "Endothelial dysfunction through genetic deletion or inhibition of the G protein-coupled receptor Mas: a new target to improve endothelial function," Journal of Hypertension, vol. 25, no. 12, pp. 2421-2425, 2007.

[74] Y. Wang, C. Qian, A. J. M. Roks et al., "Circulating rather than cardiac angiotensin-(1-7) stimulates cardioprotection after myocardial infarction," Circulation, vol. 3, no. 2, pp. 286-293, 2010.

[75] L. Ebermann, F. Spillmann, M. Sidiropoulos et al., "The angiotensin-(1-7) receptor agonist AVE0991 is cardioprotective in diabetic rats," European Journal of Pharmacology, vol. 590, no. 1-3, pp. 276-280, 2008.

[76] S. Heringer-Walther, K. Eckert, S. Schumacher et al., "Angiotensin-(1-7) stimulates hematopoietic progenitor cells in vitro and in vivo," Haematologica, vol. 94, no. 6, pp. 857-860, 2009.

[77] W. J. Petty, A. A. Miller, T. P. McCoy, P. E. Gallagher, E. A. Tallant, and F. M. Torti, "Phase I and pharmacokinetic study of angiotensin-(1-7), an endogenous antiangiogenic hormone," Clinical Cancer Research, vol. 15, no. 23, pp. 7398-7404, 2009.

[78] K. E. Rodgers, J. Oliver, and G. S. DiZerega, "Phase I/II dose escalation study of angiotensin 1-7 [A(1-7)] administered before and after chemotherapy in patients with newly diagnosed breast cancer," Cancer Chemotherapy and Pharmacology, vol. 57, no. 5, pp. 559-568, 2006. 
[79] J. L. Grobe, A. P. Mecca, H. Mao, and M. J. Katovich, "Chronic angiotensin-(1-7) prevents cardiac fibrosis in DOCA-salt model of hypertension," American Journal of Physiology, vol. 290, no. 6, pp. H2417-H2423, 2006.

[80] A. J. Ferreira, V. Shenoy, Y. Qi et al., "Angiotensin-converting enzyme 2 activation protects against hypertension-induced cardiac fibrosis involving extracellular signal-regulated kinases," Experimental Physiology, vol. 96, no. 3, pp. 287-294, 2011.

[81] C. Schindler, P. Bramlage, W. Kirch, and C. M. Ferrario, "Role of the vasodilator peptide angiotensin-(1-7) in cardiovascular drug therapy," Vascular Health and Risk Management, vol. 3, no. 1, pp. 125-137, 2007. 

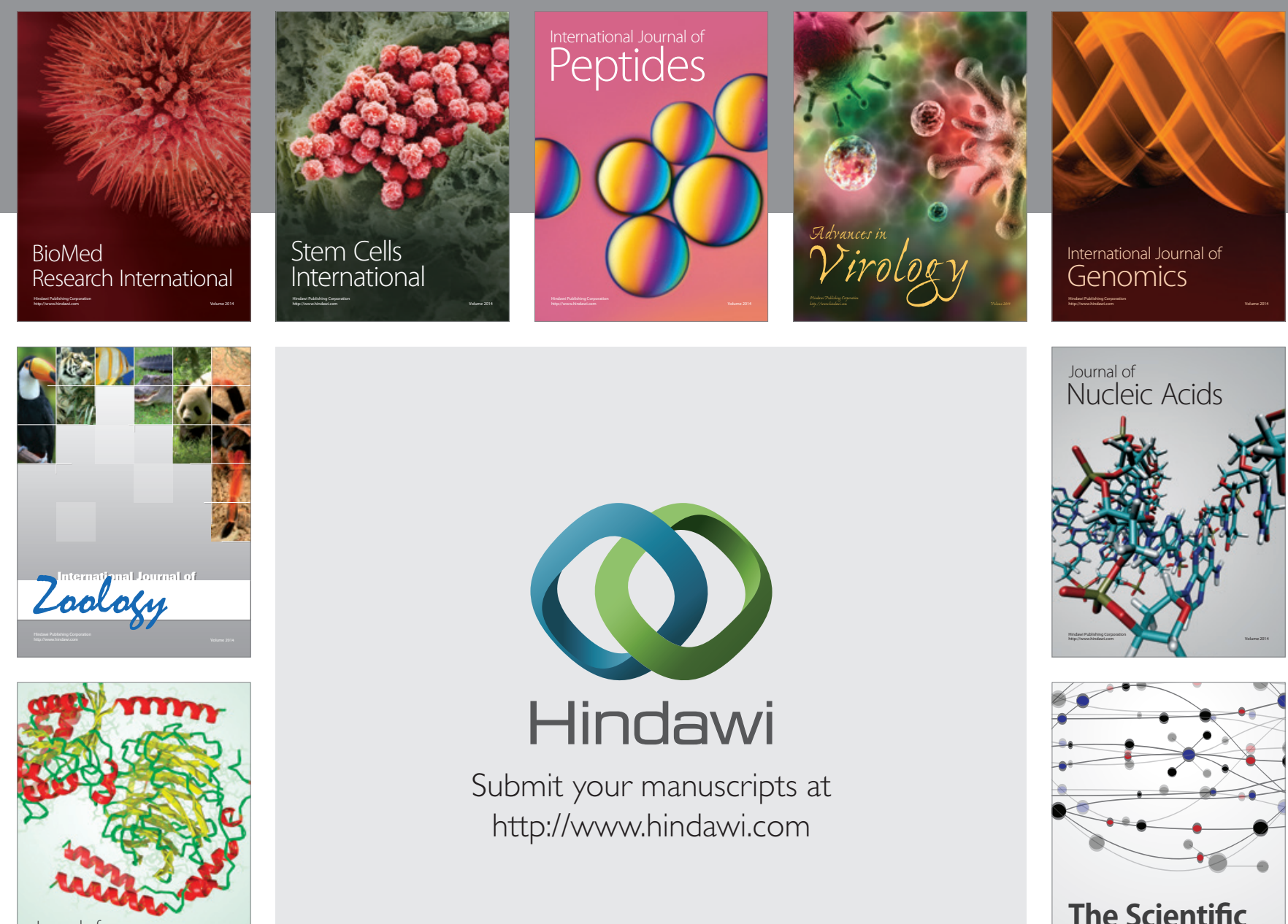

Submit your manuscripts at

http://www.hindawi.com

Journal of
Signal Transduction
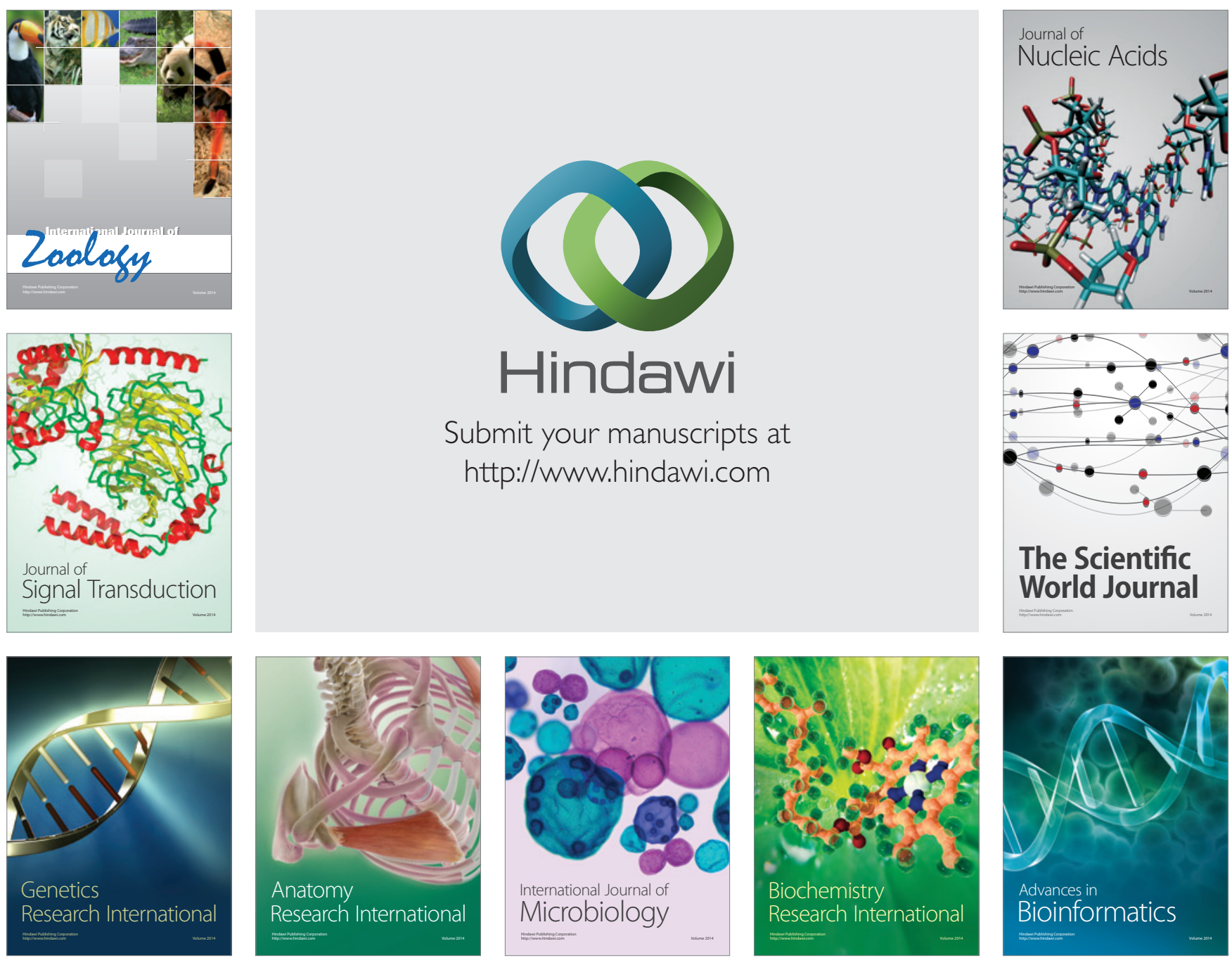

The Scientific World Journal
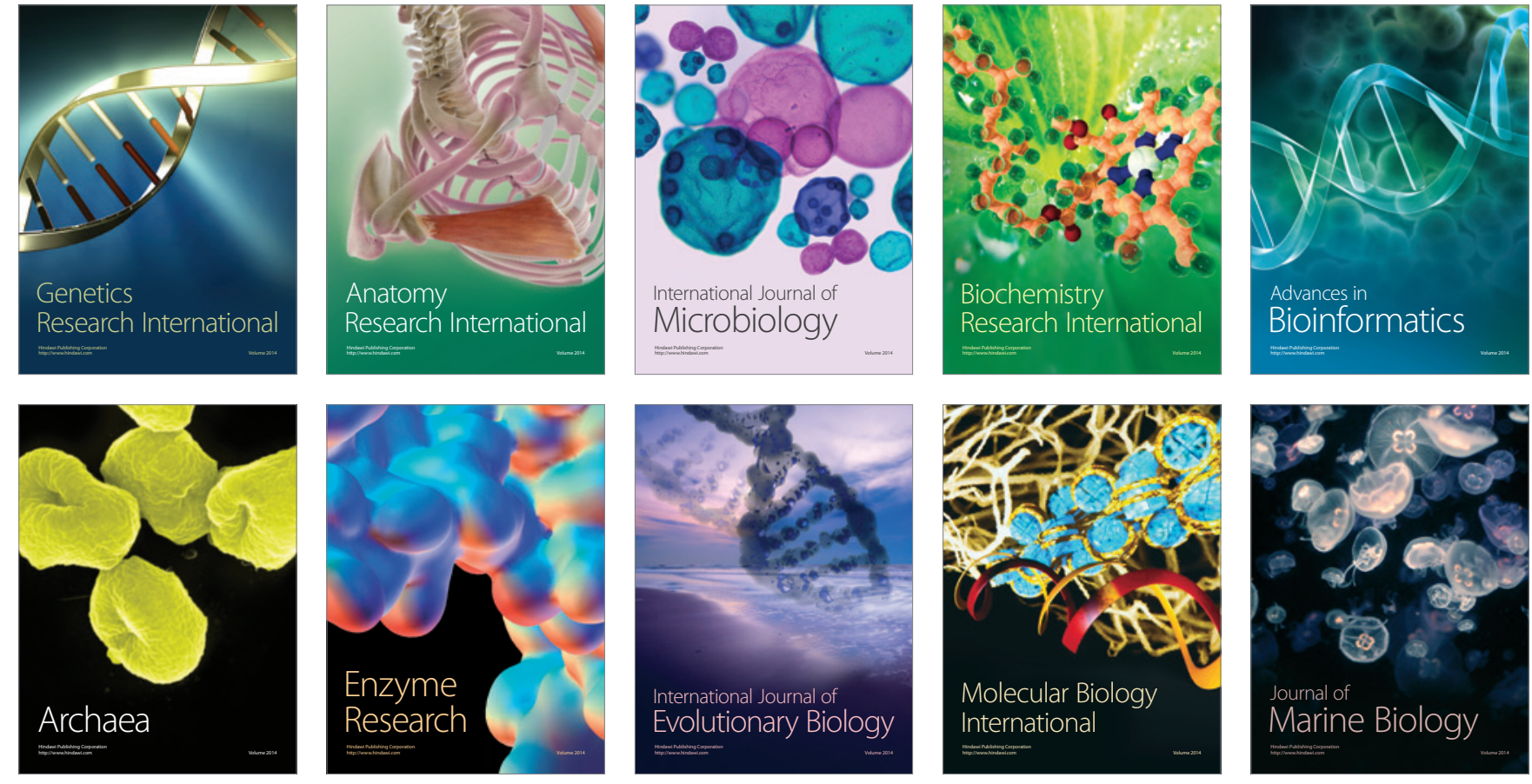